\title{
Indução de resistência sistêmica por rizobactérias em cultivos hidropônicos ${ }^{1}$
}

\author{
Fernanda Souza Bernardes²; Flávia Rodrigues Alves Patrício ${ }^{3}$; Amaury Silva Santos ${ }^{4}$; Sueli dos Santos Freitas
}

${ }^{1}$ Parte da dissertação de mestrado da primeira autora, apresentada ao IAC em abril de 2006. ${ }^{2}$ Centro de Energia Nuclear na Agricultura (CENA/ USP) / Laboratório de Genética de Microrganismos (ESALQ/USP), Pós-graduanda; ${ }^{5}$ Instituto Agronômico (IAC), Campinas, SP; ${ }^{4}$ Instituto Biológico (IB), Caixa Postal 28, Campinas, SP, CEP 13001-970; ${ }^{5}$ Embrapa Tabuleiros Costeiros, Aracaju, SE;

Autora para correspondência: Sueli dos Santos Freitas (sfreitas@iac.sp.gov.br).

Data de chegada: 17/03/2006. Aceito para publicação em: 01/01/2010.

1338

\section{RESUMO}

Bernardes, F.S.; Patrício, F.R.A.; Santos, A.S.; Freitas, S.S. Indução de resistência sistêmica por rizobactérias em cultivos hidropônicos Summa Phytopathologica, v.36, n.2, p.115-121, 2010.

Rizobactérias do grupo fluorescente de Pseudomonas spp. foram selecionadas quanto a sua capacidade na promoção de crescimento em plântulas de alface (Lactuca sativa L.) e atividade antagônica contra Pythium aphanidermatum a partir de teste in vitro. Em seguida, em sistema hidropônico, foi avaliada a aplicação prévia dos isolados visando reduzir os danos provocados por $P$. aphanidermatum em pepino (Cucumis sativus) por resistência sistêmica induzida (RSI), pela adoção da técnica "raízes subdivididas". As variáveis massa da matéria seca (parte aérea e raízes) e comprimento radicular foram utilizadas na avaliação. A produção de compostos antagônicos e/ou promotores de crescimento pelos isolados de Pseudomonas spp. fluorescente foi verificada de modo a associar sua atividade com os resultados obtidos nos testes in vitro e em hidroponia. No experimento in vitro os isolados Ps $140 \mathrm{~B}$ e Ps $140 \mathrm{C}$ proporcionaram maior crescimento das plantas (raiz e hipocótilo) de alface nos tratamentos com e sem patógeno. Alguns dos isolados avaliados no experimento hidropônico demonstraram uma possível expressão da RSI. Não houve correspondência entre os compostos produzidos e a promoção de crescimento vegetal ou controle da doença.

Palavras-chave adicionais: Pseudomonas spp., Pythium aphanidermatum, Lactuca sativa L., Cucumis sativus L., enzimas hidrolíticas.

\section{ABSTRACT}

Bernardes, F.S.; Patrício, F.R.A.; Santos, A.S.; Freitas, S.S. Induction of systemic resistance by rhizobacteria in hydroponic system. Summa Phytopathologica, v.36, n.2, p.115-121, 2010.

Rhizobacteria of the fluorescent group of Pseudomonas spp. were selected for both their capacity in the growth promotion of lettuce seedlings (Lactuca sativa L.) and antagonistic activity against Pythium aphanidermatum from test in vitro. Then, in hydroponic system was assayed the previous application of the Pseudomonas strains in order to reduce damages caused by $P$. aphanidermatum in cucumber (Cucumis sativus) for induced systemic resistance (ISR), using a technical splitroot. The variables shoots and roots dry weight and root length were used in evaluation. The production of antagonistic and/or growth promoters compounds by rhizobacteria strains was observed to associate its activity with the results obtained in the tests under hydroponic system and in vitro conditions. In the in vitro experiment, strains Ps $140 \mathrm{~B}$ and Ps $140 \mathrm{C}$ provided the largest development of plants (root and hypocotyls) in the treatments with and without pathogen. Some strains tested indicating a possible expression of ISR in in vivo experiments. No correspondence among the compounds produced by rhizobacteria, plant growth promotion and bioprotection was detected.

Keywords: Pseudomonas spp., Pythium aphanidermatum, Lactuca sativa L., Cucumis sativus L., hidrolytic enzymes.

Pseudomonas spp. do grupo fluorescente são facilmente distinguíveis de outras rizobactérias, quando cultivadas em meio B de King (11), devido a sua capacidade em produzir pigmento verde-amarelado fluorescente sob luz ultravioleta (23). Essas rizobactérias são capazes de produzir compostos como hormônios, antibióticos, enzimas e sideróforos; são classificadas como "rizobactérias promotoras de crescimento de plantas" (RPCPs) seja por modo direto, quando na ausência de patógeno, ou indireto, pela supressão do mesmo (27). A capacidade de adaptação metabólica e habilidade em produzir compostos, permitem que esse grupo de rizobactérias possam se adequar ao competitivo ambiente rizosférico, podendo ser empregadas no controle biológico de patógenos (14).
Segundo van Loon et al. (25), quando uma RPCPs coloniza a raiz, moléculas constituintes da célula bacteriana ou por ela sintetizadas agem como sinalizadores de novas rotas metabólicas. Essas moléculas ativam genes promotores de compostos de defesa, levando à expressão da resistência sistêmica induzida (RSI). Os mecanismos de defesa relacionados à RSI mediados por RPCPs podem ser estruturais, como o aumento da lignificação da parede celular, dificultando a entrada e colonização do patógeno ou bioquímicos pela presença de enzimas antioxidantes (20).

O gênero Pythium, pela nova classificação e caracterização de suas fases reprodutivas, difere dos fungos verdadeiros e pertence ao Reino Chromista (28). O Peronosporomiceto 
Pythium aphanidermatum (Edson) Fitzp. está entre os principais patógenos causadores da podridão radicular em cultivos hidropônicos, seus zoósporos são adaptados ao ambiente aquáticos e estimulados por exsudados radiculares. $\mathrm{O}$ processo de infecção e colonização dos tecidos ocorre em menos de 24 horas. A principal forma de controle desse patógeno, que se caracteriza pela agressividade de infestação, é a preventiva $(10,15)$.

Sistemas hidropônicos apresentam alta umidade, densidade de cultivo e disponibilidade de nutrientes, fatores que favorecem o estabelecimento de patógenos. Entretanto, essas mesmas condições também são benéficas à introdução e permanência de microrganismos que atuam no controle biológico (15).

Os objetivos deste trabalho foram: selecionar isolados de Pseudomonas spp. fluorescentes que promovam crescimento vegetal e/ou atividade antagônica a $P$. aphanidermatum a partir de testes in vitro; avaliar a aplicação prévia de isolados de Pseudomonas spp. em sistema hidropônico, na redução dos danos provocados por $P$. aphanidermatum por RSI a partir da técnica "raízes-subdivididas" e avaliar a produção de compostos potencialmente antagônicos como ácido hidrociânico (HCN), $\beta$-1,3-glicanase, pectinase, celulase e o promotor de crescimento ácido indol-acético (AIA).

\section{MATERIAL E MÉTODOS}

O experimento in vitro foi realizado no Laboratório de Microbiologia do Solo do Instituto Agronômico (IAC). Os experimentos in vivo foram desenvolvidos em casa de vegetação localizada no Centro Experimental do IAC.

\section{Experimento in vitro}

Sementes de alface crespa, cv. Verônica foram desinfectadas em solução de hipoclorito de sódio a $1 \%$. Após sucessivas lavagens em água destilada esterilizada, as sementes foram transferidas para placas de Petri contendo papel filtro, previamente umedecido e esterilizado. As sementes permaneceram nas placas por 24 horas em temperatura ambiente para germinação.

Sessenta isolados de Pseudomonas spp. fluorescente pertencentes à coleção de RPCPs do Instituto Agronômico (IAC), em Campinas (SP), foram transferidos para tubos de ensaio contendo meio $\mathrm{B}$ de King sólido e mantidos a $28^{\circ} \mathrm{C}$ por 24 horas. Uma "alçada" da colônia bacteriana foi transferida para tubos contendo $5 \mathrm{~mL}$ de solução de $\mathrm{MgSO}_{4}$ a $0,01 \mathrm{~mol} \cdot \mathrm{L}^{-1}$ e homogeneizados em agitador mecânico. Sementes prégerminadas foram adicionadas às suspensões bacterianas, permanecendo por 45 minutos.

$\mathrm{O}$ inóculo de $P$. aphanidermatum, cedido pelo Laboratório de Fitopatologia do Instituto Biológico, em Campinas (SP), foi cultivado em placas de Petri contendo meio V8 e mantido a $28^{\circ} \mathrm{C}$ por 96 horas. Placas de Petri contendo ágar-água receberam em seu centro um disco de $10 \mathrm{~mm}$ contendo o micélio do patógeno. As sementes pré-germinadas de alface que receberam as rizobactérias foram distribuídas (10 sementes/placa) em torno do patógeno. As placas permaneceram em temperatura ambiente por 96 horas. Os comprimentos das raízes e dos hipocótilos foram avaliados. O delineamento foi o inteiramente casualizado, com 5 repetições, sendo cada parcela representada por uma placa. Para cada isolado, prepararam-se 10 placas, cinco com o patógeno e cinco sem ele.

\section{Experimento in vivo}

Sementes de pepino japonês híbrido (cv. Hokushin), após assepsia em solução de hipoclorito a $2 \%$ e sucessivas lavagens com água destilada esterilizada, foram colocadas para germinar em placas contendo papel filtro previamente esterilizado e umedecido. A solução nutritiva foi formulada conforme exigências nutricionais da cultura. No oitavo dia após a germinação, as plântulas foram transferidas para o sistema hidropônico. A divisão do sistema radicular e a aplicação da suspensão bacteriana foram realizadas no vigésimo e vigésimo terceiro dia após a germinação, respectivamente.

As rizobactérias foram cultivadas em frascos de Erlenmeyer contendo $125 \mathrm{~mL}$ de meio B de King, a $28^{\circ} \mathrm{C}$ por 48 horas sob agitação. Em seguida, os meios de cultura foram centrifugados durante 15 minutos a $3000 \mathrm{x}$ g. O sobrenadante foi descartado e o pellet foi ressuspenso em $50 \mathrm{~mL}$ de solução de $\mathrm{MgSO}_{4}$ a $0,01 \mathrm{~mol} . \mathrm{L}^{-1}$. Aplicaram-se $10 \mathrm{~mL}$ da suspensão em $2 \mathrm{~L}$ de água, volume do recipiente hidropônico. A concentração bacteriana (in vitro e in vivo) foi estimada a partir da contagem do número de unidades formadoras de colônia (UFC) por diluição e plaqueamento em meio B de King.

No primeiro experimento foram utilizados os isolados Ps140B, Ps140C, Ps141A, Ps142A, Ps851D, Ps852B, Ps852C, Ps857C, Ps864C, Ps865A, Ps866A, Ps866B e Ps871B, escolhidos por promover ou não o crescimento vegetal em alface. No segundo experimento foram selecionados alguns isolados testados no primeiro experimento para confirmação dos resultados obtidos quanto à promoção de crescimento ou controle da doença. Isolados que apresentaram caráter benéfico somente in vitro também foram escolhidos. Desse modo, no segundo experimento, os isolados foram: Ps21B, Ps32A, Ps44A, Ps45A, Ps63A, Ps89, Ps140B, Ps140C, Ps141A, Ps142A, Ps142B, Ps143C e Ps852C.

O patógeno $P$. aphanidermatum com 96 horas de crescimento sobre meio $\mathrm{V} 8$ a $28^{\circ} \mathrm{C}$ foi transferido na forma de discos de 10 $\mathrm{mm}$ ( $25 \mathrm{discos} /$ frasco) para frascos Erlenmeyer contendo 50 $\mathrm{mL}$ de água destilada esterilizada. Estes permaneceram imersos por mais 96 horas a $28^{\circ} \mathrm{C}$ para a formação dos zoósporos. A suspensão obtida foi aplicada nos vasos hidropônicos aos 30 dias após a germinação. O número de zoósporos foi determinado em hemacitômetro após adição de $1 \mathrm{~mL}$ de Tween 40 em $4 \mathrm{~mL}$ da suspensão.

Dez dias após a aplicação do patógeno, procedeu-se à coleta das plantas, as quais tiveram seus conjuntos de raízes avaliados: massa da matéria seca (parte aérea e raízes) e o comprimento radicular.

O delineamento dos experimentos in vivo foi o inteiramente casualizado, com 4 repetições por tratamento. Cada parcela representava uma planta com raízes subdivididas, formando dois conjuntos de raízes, no qual um conjunto recebeu a aplicação da suspensão bacteriana e o outro o inóculo do patógeno. Os controles foram representados por plantas com e sem patógeno, ambos sem aplicação da rizobactéria.

\section{Produção de compostos}

Adotou-se uma avaliação qualitativa, utilizando duas repetições para cada teste. Foram determinados os seguintes 
metabólitos: ácido indol-acético (AIA), segundo Bric et al. (2); produção de $\beta$-1,3-glucanase de acordo com Renwick et al. (19); e a produção de ácido hidrociânico $(\mathrm{HCN})$, pectinase e celulase, pela metodologia descrita por Cattelan et al. (3).

\section{Análise Estatística}

Todos os resultados obtidos nos experimentos in vitro e in vivo foram submetidos à análise de variância e comparação das médias pelo teste de Tukey a $5 \%$. Os valores de porcentagem foram previamente transformados pela aplicação do arcsen $\sqrt{\mathrm{x} / 100}$.

\section{RESULTADOS E DISCUSSÃO}

\section{Experimento in vitro}

As rizobactérias utilizadas neste trabalho foram isoladas da rizosfera de várias espécies vegetais como alface, algodão, café, tomate, soja. Entretanto, estudos anteriores de inoculação e reisolamento mostraram que não existe especificidade entre estes isolados e uma determinada planta hospedeira, sendo capazes de colonizar a rizosfera de diferentes espécies vegetais $(22 ; 6)$. Desse modo, visando otimizar os testes in vitro, optouse por trabalhar com alface. Já em casa de vegetação foram utilizadas plantas de pepino, sendo essa espécie muito empregada em estudos com $P$. aphanidermatum.

Das 60 rizobactérias inoculadas em sementes prégerminadas de alface, constatou-se que os isolados Ps 21C, Ps 45C, Ps 51A, Ps 44A, Ps 89, Ps 140B, Ps $140 \mathrm{C}$ e Ps $857 \mathrm{C}$ promoveram crescimento radicular na ausência e presença do patógeno (Figura 1). Destes, apenas os isolados Ps 140B e Ps 140C - proporcionaram maior desenvolvimento radicular e do hipocótilo (dados não mostrados) em plantas de alface nos tratamentos sem e com patógeno.

$\mathrm{O}$ contato direto entre rizobactéria e patógeno permitiria que o antagonismo se manifestasse pela produção de algum composto antimicrobiano ou pela competição por nutrientes. As condições de teste incluem a planta, o que o diferencia de um teste de confrontação direto, patógeno e potencial agente de controle biológico. Essa pode ser uma forma de facilitar os testes de seleção de agentes antagônicos a patógenos, desde que os resultados obtidos correspondam aos verificados em condições de casa de vegetação.

O crescimento radicular dos controles de alguns grupos avaliados não apresentou diferenças entre os tratamentos na presença e ausência do patógeno, como se a doença não houvesse ocorrido. Supõe-se que o patógeno não tenha entrado em contato com a raiz, ou o tenha tardiamente, a ponto de não comprometer o crescimento vegetal até a avaliação. Vários parâmetros como nutrientes, o pH do meio e a temperatura de incubação podem influenciar no comportamento bacteriano prejudicando a síntese de compostos que possam atuar durante a atividade antagônica, inviabilizando sua ocorrência em condições in vitro (24).

No experimento in vitro, o número de UFC presentes na suspensão, onde as sementes pré-germinadas foram imersas foi de $0,84 \times 10^{8} / \mathrm{mL}$. Nessa concentração as células bacterianas reduzem o seu crescimento, dando início à fase estacionária. Segundo Vining (26), a produção de alguns metabólitos secundários com caráter antimicrobiano, sob condições in vitro, inicia-se no final da fase logarítmica e princípio da fase estacionária. Embora não se tenha verificado o número de células presentes no tecido da planta, após a fase de incubação, acreditase que a síntese de metabólitos com atividade antagônica comece tão logo o processo de colonização do tecido vegetal se inicia, facilitando o estabelecimento das rizobactérias no ambiente.

\section{Experimentos in vivo}

Quando o tratamento controle que recebeu a inoculação do patógeno (CCP) foi comparado com os demais tratamentos expostos ao $P$. aphanidermatum e que, também, receberam o inóculo das rizobactérias em uma das partes do sistema radicular subdividido, observou-se que não houve diferença entre as massas da matéria seca das raízes (Figura 2). Porém, ao confrontar com o tratamento controle na ausência do patógeno (CSP) nota-se que houve uma redução significativa na massa da matéria seca das raízes infectadas por $P$. aphanidermatum $\mathrm{e}$ tratadas com os isolados Ps 21B, Ps 44A, Ps 45A, Ps 63A, Ps $140 \mathrm{C}$ e Ps $142 \mathrm{~B}$.

A observação dos resultados da massa da matéria seca das raízes dentro de cada tratamento revelou que os isolados Ps 44A, Ps 89, Ps 140B, Ps $141 \mathrm{~A}$, e Ps $852 \mathrm{C}$ não apresentaram diferenças (Figura 2). Essa resposta obtida pela comparação dos efeitos da ausência e presença do patógeno nas raízes de uma mesma planta ("raízes subdivididas") pode indicar um modo de controle via resistência sistêmica induzida. A técnica de raízes-subdivididas permite que os microrganismos rizobactéria e patógeno se mantenham separados espacialmente. Desse modo, não há o controle direto do patógeno pela ação de alguma substância antagônica produzida pela bactéria.

Sideróforos, assim como o ácido salicílico, podem ativar o sistema de defesa das plantas (13). Porém, para o desenvolvimento da cultura em sistema hidropônico, há na solução de cultivo a presença de ferro. Sideróforos são produzidos pelas rizobactérias em baixa concentração ou total ausência de ferro no ambiente. Desse modo, é possível que nesse ambiente a ocorrência de RSI em plantas tratadas com Pseudomonas sp. e cultivadas em solução nutritiva se deva a outro fator.

Há diversos relatos que evidenciam o efeito benéfico das rizobactérias via indução do sistema de defesa em cucurbitáceas. Plantas de pepino tratadas com Pseudomonas sp. apresentaram redução nos sintomas provocados por $P$. aphanidermatum pelo atraso e/ou diminuição na colonização do patógeno. Esse fenômeno foi atribuído, embora não comprovado, à ativação de mecanismos de defesa na planta de ordem física e/ou bioquímica (5). Zhou \& Paulitz (29) verificaram a ocorrência de RSI por Pseudomonas spp. em plantas de pepino uma semana antes da aplicação do inóculo de $P$. aphanidermatum, pela adoção da técnica raízes-subdivididas em cultivo hidropônico.

Alguns mecanismos de defesa vegetal só são expressos após a inoculação do patógeno no hospedeiro que tenha recebido tratamento prévio com algum composto ou microrganismo que apresente caráter indutor. Esse agente indutor iria predispor a planta a ativar mais rapidamente respostas de defesa quando em presença do patógeno. Esse mecanismo de ação tem sido comumente observado quando se estuda a interação entre rizobactérias e seu hospedeiro frente a algum patossistema (17).

Observou-se que algumas rizobactérias que promoveram o crescimento radicular em alface, no experimento in vitro, como os isolados Ps 44A, Ps 89, Ps 140B e Ps 140C, não apresentaram a mesma resposta no experimento in vivo (Figura 

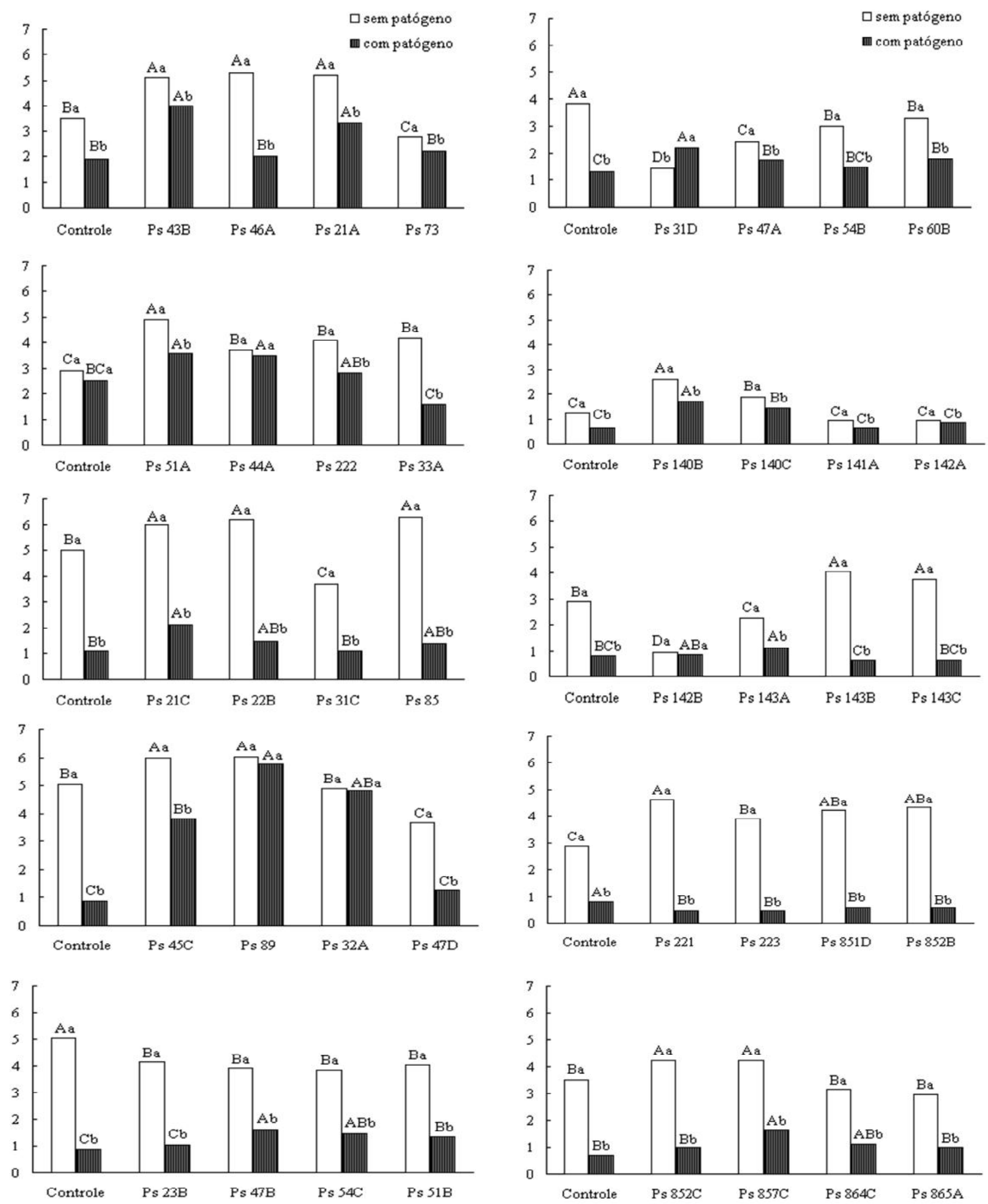

Figura 1. Comprimento radicular $(\mathrm{cm})$ de plantas de alface, in vitro, tratadas com isolados de Pseudomonas spp. fluorescentes, na presença e ausência do inóculo de Pythium aphanidermatum. Médias de 10 repetições. Valores seguidos de letras iguais não diferem entre si por Tukey (P $\leq$ 0,05). Letras maiúsculas comparam o efeito da inoculação das rizobactérias com e sem patógeno. Letras minúsculas comparam, dentro de cada tratamento com bactéria, o efeito da inoculação. 


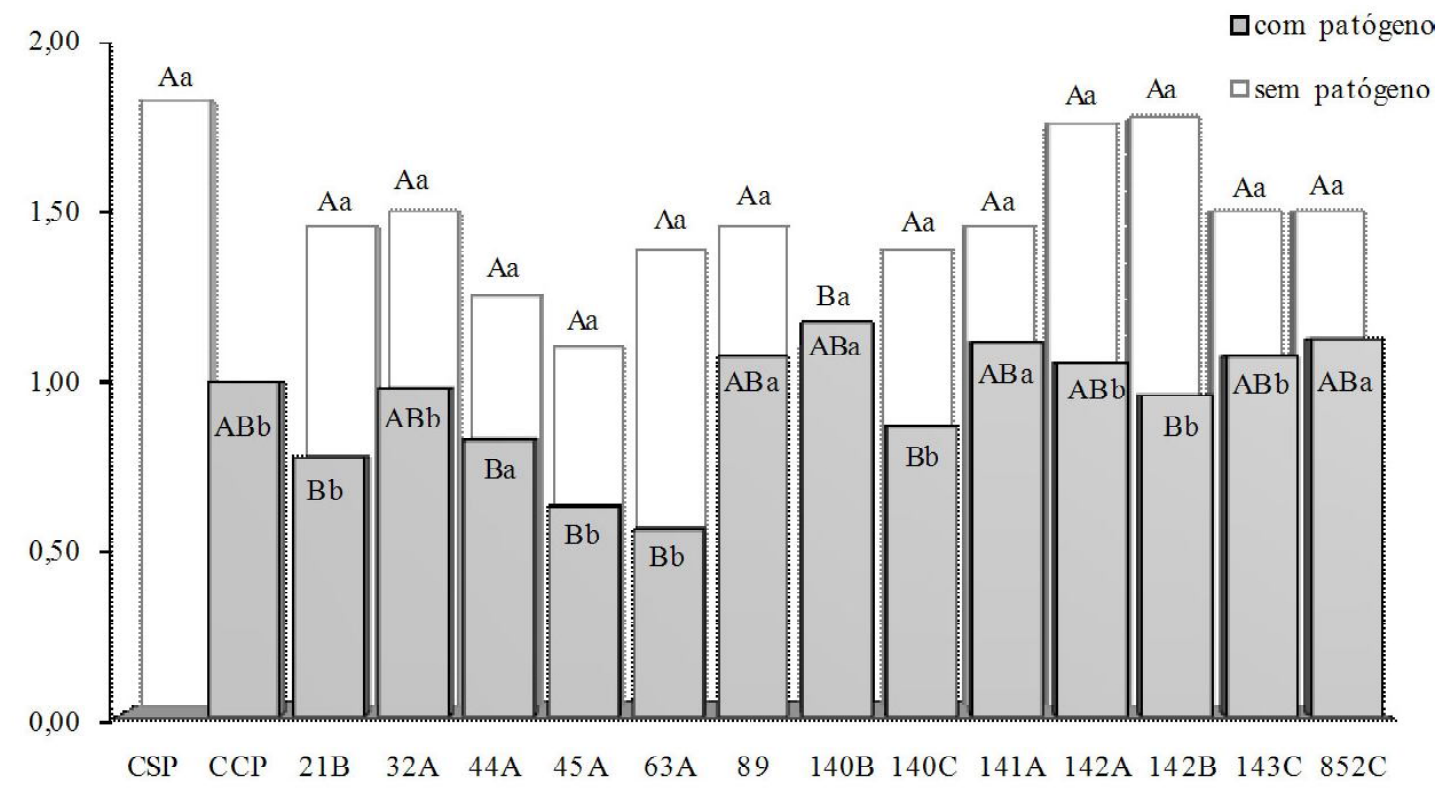

Figura 2. Massa da matéria seca (g) das raízes de plantas de pepino cultivadas em sistema hidropônico pela técnica raízes subdivididas, onde parte das raízes recebeu o inóculo de Pythium aphanidermatum e a outra o inóculo de isolados de Pseudomonas spp. fluorescentes. Médias de 4 repetições. Experimento 2.

* CSP: controle sem patógeno; CCP: controle com patógeno.

** Valores seguidos de letras iguais não diferem entre si por Tukey $(\mathrm{P} \leq 0,05)$. Letras maiúsculas comparam, entre tratamentos de inoculação do patógeno, o efeito da inoculação das rizobactérias. Letras minúsculas comparam, dentro de cada tratamento com bactéria, o efeito da inoculação do patógeno.

1). Contudo, esse comportamento distinto in vitro e in vivo é confirmado por dados da literatura (7). Nenhum dos isolados se mostrou promotor de crescimento vegetal em relação ao tratamento controle sem patógeno (CSP). Segundo Sharma \& Nowak (21), a resistência sistêmica induzida é um processo conseguinte à promoção de crescimento, possivelmente, dependente da colonização e sensibilização do hospedeiro.

As concentrações dos zoósporos inoculados no primeiro e segundo experimento foram de 7,5 x $10^{4}$ zoósporos/mL e 3,4 x $10^{4}$ zoósporos $/ \mathrm{mL}$ respectivamente. Essas concentrações estão dentro do padrão utilizado em outros estudos, que variam de $10^{3}$ a $10^{6}$ zoósporos/mL $(4 ; 29)$. O inóculo das rizobactérias lançadas sobre a água de irrigação do vaso hidropônico apresentava uma concentração de $0,53 \times 10^{8} \mathrm{UFC} / \mathrm{mL}$. Embora, a concentração de rizobactérias não tenha sido determinada ao término do experimento, segundo Raaijmakers et al. (18), a população mínima necessária de RPCPs para que ocorra a RSI é de $10^{5}$ UFCs, ou seja, é preciso que ocorra uma sinalização "quorum sensing" para que a produção de compostos indutores comecem a ser sintetizados pelas rizobactérias em uma concentração que possa ser reconhecida pela planta. De acordo com Paulitz et al. (16), o tempo de inoculação e estabelecimento bacteriano no hospedeiro, o intervalo de aplicação do patógeno, a presente concentração dos microrganismos, assim como, a determinação do período de amostragem vegetal para análise, são fatores que influenciam na resposta a ser obtida durante o estudo do processo de defesa vegetal.

\section{Produção de compostos}

Pseudomonas spp. fluorescentes podem produzir uma grande variedade de metabólitos secundários antagônicos a fungos fitopatôgenicos como antibióticos, sideróforos, enzimas hidrolíticas, compostos voláteis que inibem o crescimento micelial etc.

No presente trabalho determinou-se a produção de cinco compostos com caráter antagônico ou promotor de crescimento vegetal. A substância mais produzida foi o ácido indol-acético (AIA) observado em $40 \%$ dos isolados; a produção de ácido hidrociânico ( $\mathrm{HCN}$ ) foi verificada em nove isolados, a pectinase por apenas um isolado. A celulase não foi produzida por nenhuma das rizobactérias. Observou-se que $20 \%$ dos isolados produzem mais de uma das substâncias analisadas (Tabela 1).

No experimento in vitro $13 \%$ dos tratamentos que foram expostos ao patógeno e apresentaram maior crescimento radicular, estavam inoculados com rizobactérias produtoras de $\beta-1,3$ glucanase. As glucanas são o principal componente da parede celular de $P$. aphanidermatum e a enzima $\beta-1,3$ glucanase é responsável pela degradação dessa molécula. Nesse caso, pode ser que o controle do patógeno deva-se à presença dessa enzima. A $\beta-1,3$ glucanase foi produzida por 16 isolados dos isolados avaliados. Fridlender et al. (9) verificaram que Pseudomonas cepacia, produtora de $\beta-1,3$ glucanase, inibiu o crescimento de Rhizoctonia solani, Sclerotium roffsii e Pythium ultimum.

Bagnasco et al. (1) concluíram que o principal fator de controle de fungos patogênicos em leguminosas foi devido à produção de $\mathrm{HCN}$, pois isolados de $P$. fluorescens produtores de sideróforos e de HCN não tiveram sua atividade antagônica afetada quando na presença de ferro. Apesar de o HCN ser um ácido volátil importante na inibição de agentes patogênicos, somente os isolados Ps $21 \mathrm{~A}$, Ps 47A e Ps 47B, produtores 
Tabela 1. Análise dos compostos produzidos pelas rizobactérias de Pseudomonas spp. fluorescentes, em meios de cultura sólidos.

\begin{tabular}{|c|c|c|c|c|c|c|c|c|c|c|c|}
\hline $\mathrm{Rzb}^{1}$ & $\mathrm{HCN}^{2}$ & AIA $^{3}$ & $\beta$-gl. ${ }^{4}$ & Pect. $^{5}$ & Cel. ${ }^{6}$ & $\mathbf{R z b}^{1}$ & $\mathrm{HCN}^{2}$ & AIA $^{3}$ & $\beta$-gl. ${ }^{4}$ & Pect. ${ }^{5}$ & Cel. ${ }^{6}$ \\
\hline Ps21A & + & - & - & - & - & $60 \mathrm{~B}$ & - & - & - & - & - \\
\hline Ps21B & + & + & - & - & - & $62 \mathrm{~A}$ & - & + & - & - & - \\
\hline Ps $21 \mathrm{C}$ & - & - & - & - & - & $63 \mathrm{~A}$ & - & + & - & + & - \\
\hline Ps $22 \mathrm{~A}$ & + & + & - & - & - & 70 & - & + & + & - & - \\
\hline Ps22B & - & + & - & - & - & 73 & - & + & + & - & - \\
\hline Ps23B & - & - & - & - & - & 85 & - & + & + & - & - \\
\hline $\operatorname{Ps} 23 \mathrm{C}$ & - & + & + & - & - & 89 & - & + & + & - & - \\
\hline Ps31B & - & - & - & - & - & 91 & - & - & - & - & - \\
\hline Ps31C & - & - & - & - & - & 92 & - & - & - & - & - \\
\hline Ps31D & - & - & - & - & - & $140 \mathrm{~B}$ & - & - & - & - & - \\
\hline Ps $32 \mathrm{~A}$ & - & - & - & - & - & $140 \mathrm{C}$ & - & - & - & - & - \\
\hline Ps $33 \mathrm{~A}$ & - & + & - & - & - & $141 \mathrm{~A}$ & - & - & - & - & - \\
\hline Ps $34 \mathrm{C}$ & - & + & - & - & - & $142 \mathrm{~A}$ & - & - & - & - & - \\
\hline Ps41B & + & - & - & - & - & $142 \mathrm{~B}$ & - & - & - & - & - \\
\hline Ps42B & + & - & - & - & - & $143 \mathrm{~A}$ & - & + & - & - & - \\
\hline Ps43B & - & - & - & - & - & 143B & - & + & - & - & - \\
\hline Ps $44 \mathrm{~A}$ & - & - & + & - & - & $143 \mathrm{C}$ & - & - & - & - & - \\
\hline Ps45 A & - & - & + & - & - & 221 & - & - & + & - & - \\
\hline Ps45C & - & - & - & - & - & 222 & - & - & + & - & - \\
\hline Ps46A & - & - & - & - & - & 223 & - & + & - & - & - \\
\hline Ps47A & + & + & - & - & - & $851 \mathrm{D}$ & - & + & - & - & - \\
\hline Ps47B & + & + & - & - & - & $852 \mathrm{~B}$ & - & + & - & - & - \\
\hline Ps47C & - & - & - & - & - & $852 \mathrm{C}$ & - & + & - & - & - \\
\hline Ps47D & - & - & - & - & - & $857 \mathrm{C}$ & - & + & - & - & - \\
\hline Ps51A & - & - & + & - & - & $864 \mathrm{C}$ & - & - & + & - & - \\
\hline Ps51B & - & - & + & - & - & $865 \mathrm{~A}$ & - & + & - & - & - \\
\hline Ps53A & + & + & - & - & - & $866 \mathrm{~A}$ & - & - & + & - & - \\
\hline Ps54A & + & - & - & - & - & $866 \mathrm{~B}$ & - & - & + & - & - \\
\hline Ps54B & - & - & - & - & - & $871 \mathrm{~B}$ & - & - & + & - & - \\
\hline Ps54C & - & + & + & - & - & W4F58 & - & - & - & - & - \\
\hline
\end{tabular}

*A presença (+) e ausência (-) dos compostos produzidos pelas ${ }^{1}$ rizobactérias como ${ }^{2}$ ácido hidrociânico, ${ }^{3}$ ácido indol-acético, ${ }^{4} \beta-1,3-$ glucanase, ${ }^{5}$ pectinase e ${ }^{6}$ celulase foram avaliadas qualitativamente pela formação do halo em torno das colônias (média de duas repetições).

dessa molécula, foram capazes de aumentar o crescimento radicular, possivelmente, pela inibição do patógeno. Kremer \& Souissi (12) observaram que rizobactérias produtoras de $\mathrm{HCN}$ influenciaram o crescimento de plântulas de alface, fato que pode ter se repetido neste experimento.

No experimento in vivo algumas das rizobactérias inoculadas são produtoras de um ou dois dos compostos avaliados. Entretanto, nenhum isolado utilizado neste experimento, produtor de HCN e pectinase, substâncias potencialmente antagônicas e que também podem ser responsáveis pela resistência sistêmica induzida (RSI), resultou em efeito benéfico às plantas. Os antibióticos produzidos por bactérias podem atuar sobre os fungos comprometendo algum processo fisiológico da célula cujo efeito pode ser fungistático ou fungicida, inibindo a germinação de esporos ou pela lise celular (24).

Embora os resultados benéficos encontrados em ambos os experimentos, in vitro e in vivo, não pudessem ser associados a presença de compostos produzidos pelas rizobactérias, as análises bioquímicas permitem selecionar isolados que apresentem maior probabilidade de serem eficientes em um processo de colonização e controle biológico. Há que se considerar que apenas algumas poucas moléculas foram pesquisadas: é possível que outras substâncias possam estar envolvidas e explicar os resultados obtidos.

\section{REFERÊNCIAS BIBLIOGRÁFICAS}

1. Bagnasco, P.; De La Fuente, L.; Gualtieri, G.; Noya, F.; Arias, A. Fluorescent Pseudomonas spp. as biocontrol agents against forage legume root pathogenic fungi. Soil Biology and Biochemistry, Oxford, v.30, n.10, p.1317-1322, 1998.

2. Bric, J. M.; Bostock, R. M.; Silverston, S. E. Rapid in situ assay for indoleacetic acid production by bacteria immobilized on a nitrocellulose membrane. Applied and Environ- 
mental Microbiology, Washington, v.57, n. 2, p.535-538, 1991 .

3. Cattelan, A. J.; Hartel, P. G.; Fuhrmann, J. J. Screening for plant growth-promoting rhizobacteria to promote early soybean growth. Soil Science Society of American Journal, Madison, v.63, n. 6, p.1670-1680, 1999.

4. Chen, C.; Bélanger, R. R.; Benhamou, N.; Paulitz, T. C. Induced systemic resistance (IRS) by Pseudomonas spp. impairs pre- and post-infection development of Pythium aphanidermatum on cucumber roots. European Journal of Plant Pathology, Holanda, v.104, n. 9, p.877-886, 1998.

5. Chen, C.; Bélanger, R. R.; Benhamou, N.; Paulitz, T. C. Defense enzymes induced in cucumber roots by treatment with plant growth-promoting rhizobacteria (PGPR) and Pythium aphanidermatum. Physiological and Molecular Plant Pathology, London, v.56, n. 1, p.13-23, 2000.

6. Freitas, S. S.; Melo, A. M. T.; Donzeli, V. P. Promoção do crescimento de alface por rizobactérias. Revista Brasileira de Ciência do Solo, Viçosa, v. 27, n. 1, p. 61-70, 2003.

7. Freitas, S. S.; Pizzinatto, M. A. Ação de rizobactérias sobre a incidência de Colletotrichum gosyipii e promoção de crescimento em plântulas de algodoeiro (Gossypium hirsutum). Summa Phytopathologica, Jaboticabal, v. 23, n. 1, p. 3641, 1997.

8. Freitas, S. S.; Vildoso, C. I. A. Rizobactérias e promoção do crescimento de plantas cítricas. Revista Brasileira de Ciência do Solo, Viçosa, v. 28, n. 6, p. 987-994, 2004.

9. Fridlender, M.; Inbar, J.; Chet, I. Biological control of soilborne plant pathogens by a $\beta$-1,3-glucanase producing Pseudomonas cepacia. Soil Biology and Biochemistry, Oxford, v.25, n. 9, p.1211-1221, 1993.

10. Glick, B.R., Penrose, D.M.; Li, J. A model for the lowering of plant ethylene concentrations by plant growth-promoting bacteria. Journal Theoreme Biology, v. 190, p. 63-68, 1998.

11. King, E. O.; Ward, M. K. e Raney, D. E. Two simple media for the demonstration of pyocyanin and fluorescin. Journal of Laboratory and Clinical Medicine, St. Louis, v.44, n. 2, p. 301-307, 1954 .

12. Kremer, R. J.; Souissi, T. Cyanide production by rhizobacteria and potential for suppression of weed seedling growth. Current Microbiology, New York, v. 43, n. 3, p.182-186, 2001.

13. Leeman, M.; Den Ouden, F. M.; Van Pelt, J. A.; Dirkx, F. P. M.; Steijl, H.; Bakker, P. A. H. M.; Schippers, B. Iron availability affects induction of systemic resistance to Fusarium wilt of radish by Pseudomonas fluorescens. Phytopathology, St. Paul, v. 86, n. 2, p. 149-155, 1996.

14. O'Sullivan, D. J.; O'Gara, F. Traits of fluorescent Pseudomonas spp. involved in suppression of plant root pathogens. Microbiological Review, Washington, v. 56, n. 6, p. 662 $676,1992$.

15. Paulitz, T. C.; Belanger, R. R. Biological control in greenhouse systems. Annual Review of Phytopathology, Palo Alto, v. 39, n. 1, p. 103-133, 2001.

16. Paulitz, T. C.; Zhou, T.; Rankin, L. Selection of rhizosphere bacteria for biological control of Pythium aphanidermatum on hydroponically grown cucumber. Biological Control, Amsterdam, v. 02, n. 3, p. 226-237, 1992.

17. Pieterse, C. M. J.; Van Pelt, J. A.; Van Wees, S. C. M.; Ton, J.; Verhagen, B. W. M.; Léon-Kloosterziel, K.; Hase, S.; De Vos, M.; Oosten, V. V.; Pozo, M.; Spoel, S.; Van Der Ent, S.; Koornneef, A.; Chalfun-Junior, A.; Resende, M. L.V.; Van Loon, L. C. Indução de resistência sistêmica por rizobactérias e comunicação na rota de sinalização para uma defesa refinada. Revisão Anual de Patologia de Plantas, Passo Fundo, v.13, n. 1, p.277-295, 2005.

18. Raaijmakers, J. M.; Leeman, M.; Van Oorschot, M. P. M.; Van der Sluis, I; Schippers, B.; Bakkers, P. A. H. M. Dose-response relationships in biological control of fusarium wilt of radish by Pseudomonas spp. Phytopathology, St. Paul, v. 85, n.10, p. 1075-1081, 1995 .

19. Renwick, A.; Campbell, R.; Coe, S. Assessment of in vivo screening systems for potential biocontrol agents of Gaeumannomyces graminis. Plant Pathology, St. Paul, v. 40, n. 4, p.524-532, 1991.

20. Romeiro, R. S.; Garcia, F. A. O. Controle Biológico de enfermidades de plantas incitadas por bactérias. Revisão Anual de Patologia de Plantas, Passo Fundo, v.11, n. 1, p.195-228, 2003 .

21. Sharma, V.; Nowak, J. Verticillium wilt suppression in tomato with pseudomonad bacterium. Canadian Journal of Microbiology, Ottawa, v. 44, n. 5, 1998.

22. Sottero, A. N.; Freitas, S. S.; Melo, A. M. T.; Trani, P. E. Rizobactérias e alface: colonização rizosférica, promoção de crescimento e controle biológico. Revista Brasileira de Ciência do Solo, Viçosa, v. 30, n. 2, p. 225-234, 2006.

23. Stanier, R. Y; Palleroni, N. J; Doudoroff, M. The aerobic pseudomonas: a taxonomic study. Journal General of Microbiology, London, v.43, n. 2, p.159-271, 1966.

24. Trivedi, P.; Pandey, A.; Palni, L. M. S. In vitro evaluation of antagonistic properties of Pseudomonas corrugate. Microbiological Research, Alemanha, v. 163, n. 3, p. 329-336, 2008.

25. Van Loon, L. C.; Bakker, P. A. H. M.; Pieterse, C. M. J. Systemic resistance induced by rhizosphere bacteria. Annual Review of Phytopathology, Palo Alto, v.36, n. 1, p. 453 483, 1998 .

26. Vining L. C. Functions of secondary metabolites. Annual Review of Microbiology, Palo Alto, v. 44, n. 1, p. 395-427, 1990 .

27. Weller, D. M. Biological control of soilborn plant pathogens in the rhizosphere with bacteria. Annual Review of Phytopathology, Palo Alto, v.26, n. 1, p.379-407, 1988.

28. West, P. V.; Appiah, A. A.; Neil, A. R. G. Advances in research on oomycete root pathogens. Physiological and Molecular Plant Pathology, London, v. 62, n. 1, p. 99-113, 2003.

29. Zhou, T.; Paulitz, T. C. Induced resistance in the biocontrol of Pythium aphanidermatum by Pseudomonads spp. on cucumber. Journal of Phytopathology, Berlin, v.142, n. 1, p.51-63, 1994 . 